\title{
Translation Techniques and Acceptability of Onomatopoeia in Herge's The Adventure of Tintin Comic
}

Inas Haninisa ${ }^{1}$, Dyah Raina Purwaningsih ${ }^{2}$, R. Pujo Handoyo ${ }^{3}$

Jenderal Soedirman University

inashanisa@gmail.com¹, dyah.purwaningsih@unsoed.ac.id², handyjojo@gmail.com ${ }^{3}$

Article History:

First Received:

$11 / 11 / 2020$

Final Revision:

$28 / 12 / 2020$

Available online:

$30 / 12 / 2020$

\begin{abstract}
This research is aimed to analyze the types of onomatopoeia, techniques of translation as well as the acceptability aspect of the translated onomatopoeia in The Adventure of Tintin comic in order to compare how English and Indonesian in naming the sound of something and know how translation techniques can affect the quality of translation products. This research used descriptive qualitative method and total sampling. This research primarily applied the theory of onomatopoeia especially the types of onomatopoeia from Thomas and Clara (2004:4), Molina and Albir's (2002: 509) theory of translation techniques and Translation Quality Assessment (TQA) proposed by Nababan (2012: 44) which focused on acceptability aspect. The result shows that there are 121 data found in 21 comic series of Tintin. There are four types of onomatopoeia which are call of animals (19\%), sound made by humans (17.3\%), sound of nature $(8.3 \%)$ and miscellaneous sound (55.4\%). Meanwhile, techniques that are used by the translator are only five techniques. The techniques consist of adaptation (5\%), borrowing (34.7\%), discursive creation (19\%), established equivalent (37.2\%), and reduction (4.1\%). At last, the translated onomatopoeia in Tintin comic are predominantly acceptable which has a total $82 \%$ of onomatopoeia, $15 \%$ belong to less acceptable, and $3 \%$ belong to unacceptable.
\end{abstract}

Keywords: Acceptability; Multimodal Translation; Onomatopoeia in Comic; The Adventure of Tintin; Translation Studies; Translation Techniques 


\section{INTRODUCTION}

Nowadays, there are so many kinds of literary work which are created in many ways. There will be a novel, prose, poetry, or even comics. Indeed, comics as the literature needed for kids and teenagers, except the interesting stories that are delivered, also provides some more attractive pictures to captivate the readers. A comic book is one of the literary works which tells about the writer's story and contains some pictures in same panels. According to Cohn (2005: 1), comics as the work which consist of images and text are created in a sequence of images. So, comics are produced by blending towards verbal and visual elements which is printed into the written form. Comics generally consist of one or more panels. Besides utterances, comics also provide expressive words to make the story more alive when the readers read it. For instances, comics also show the expression of the action or movement sounds such as drinking water, foot-step and the sound of an animal. This linguistics phenomenon is called onomatopoeia.

Onomatopoeia is the words that are produced by imitating the sounds of something. It can be an object sound or an action sound. Onomatopoeia is the language phenomenon that usually appears in our social life, but nowadays, this thing is rarely discussed. O'Grady (2005: 76) stated that onomatopoeia can be defined as all languages that have words whose sound represent an aspect of the thing that they name. In other words, onomatopoeia can be defined simply as the names of the relationship between the sounds of a word and something else around us. Thus, comics often provide the onomatopoeic expression which is conducted from the movement and the action of an object in almost every page. For instance, the sound of a cat will be described into MEOW. Thomas and Clara (2004: 4) divided types of onomatopoeia into four, such as call of animals, sound made by humans, sound of natures and miscellaneous sounds or the inanimate objects.

Additionally, onomatopoeia is produced by the creativity of humans, so that, it will be different in one culture and the others. Onomatopoeia will be different in each country because they have the different language culture and language system. Translating the onomatopoeia will not be easy between one language and the others. In this case, the problem of transferring meaning can be analyzed by using the translation study. The translator may use a certain technique in transferring the cultural language from the source text (ST) into the target text (TT). Hence, Molina and Albir (2002: 509) have elaborated 18 of the translation techniques. There are adaptation, generalization, borrowing, reduction and etc.

In fact, there are some kinds of comic that are famous in each country. One of the most popular comics throughout the world is The Adventure of Tintin. This comic was written by a Belgian cartoonist named George Prosper Remi or Herge. There are 24 comic series published in many languages. Tintin was published first in 1929 and all comics become popular throughout the world. This comic tells about the story about a young Belgian reporter named Tintin and his beloved dog named Snowy which first introduced in the Le Petit Vingtieme news in Belgium. The story tells how shrewd Tintin was when he solved the problem and criminalization which existed throughout the world. 
Now, The Adventure of Tintin comic exists in many language versions. Since each version has a different language, it also has a different onomatopoeia. The researcher chose 21 of 24 comic series of Tintin in English and Indonesian versions. The data are taken in pairs (the ST and TT) and for that reason, the researcher is interested in comparing how English and Indonesian versions naming the sound of object movement and action of characters and know how the translator translated the onomatopoeia since they both have different culture. The researcher considers in analyzing the newest topic of discussion and the different focus of research with the other related studies in order to conduct the most recent of research. Some of the previous study that discuss translation and onomatopoeia were from Flori Lestari (2014) who analyzed the types of onomatopoeia and the method of translation in the research entitled Onomatopoeia Translation in WreckIt-Ralph The Movie, also, the research from Dewi Hana Pertiwi (2015) who discuss the iconicity and types of onomatopoeia in the research entitled Translation of Onomatopoeia and Iconicity in Children Story Book: Crocoffein-Coffee of Friendship (2013). However, this research is totally different with the other previous studies that have been mentioned before since this research used different data source, the newest theory and has more specific discussion that relate to each other.

The researcher is interested in analyzing the translation techniques and acceptability level of onomatopoeia in The Adventure of Tintin comic. Therefore, through this research, the researcher wants to categorize the types of onomatopoeia, investigate the techniques that are used by the translator and the acceptability level of translated onomatopoeia in The Adventure of Tintin comic. The researcher chose The Adventure of Tintin comic as the data source of research because there are found so many of onomatopoeia. Therefore, a translator needs the specific knowledge about the onomatopoeia to deliver an equivalent and acceptable translation to the target readers since we know that onomatopoeia is a meaningless word.

\section{RESEARCH METHOD}

The research used descriptive qualitative method and total sampling, since the qualitative research is a research method that is produced the descriptive data in a word or oral from the people or the action which can be observed (Nazir, 2005). The primary data of this research are all of onomatopoeia found in 21 comic series of The Adventure of Tintin comic both in English and Indonesian versions. The questionnaires of translation acceptability assessment that are gathered from three respondents are also involved in conducting this research. The secondary data are the data and references that are obtained from some relevant books, journals, articles, and previous research which have relevant information about translation studies and onomatopoeia in comic.

In collecting the data, the methods are based on Creswell (2007: 118) that data collection is a series of interrelated activities aimed at gathering good information to answer emerging research questions. The steps are first the researcher downloaded 21 series comic both in English and Indonesian, collected the onomatopoeia in source language (ST) and target language (TL), numbered the data, prepared the questionnaire of translation acceptability assessment and selected the respondents who would be the raters. 
Afterwards, data analysis is done by the following steps. The researcher analyzed the collected data, categorized the types of onomatopoeia, identified the techniques that are used by the translator, then gathered and investigated the data that are collected from the raters.

\section{RESULT AND DISCUSSION}

There are 121 pairs of onomatopoeia found in 21 comic series in The Adventure of Tintin comic. To sum up the data analysis, the researcher categorized the result of this research briefly into the table based on types of onomatopoeia, translation techniques and the acceptability level of translated onomatopoeia which includes the scale of acceptability provided from the respondents' assessment towards the data that have been concluded by using the formula.

\section{Types of Onomatopoeia}

This sub-chapter discusses the types of onomatopoeia found in The Adventure of Tintin comic. Thomas and Clara (2004: 4) divided the types of onomatopoeia in four. There are call of animals, sound made by humans, sound of natures and miscellaneous sounds.

Table 1. Types of Onomatopoeia

\begin{tabular}{|c|c|c|c|}
\hline No. & Types of Onomatopoeia & Total & Percentages \\
\hline 1. & Call of Animal & 23 & $19 \%$ \\
\hline 2. & Sound Made by Human & 21 & $17.3 \%$ \\
\hline 3. & Sound of Nature & 10 & $8.3 \%$ \\
\hline 4. & Miscellaneous Sound & 67 & $55.4 \%$ \\
\hline \multicolumn{2}{|c|}{ Total Data } & $\mathbf{1 2 1}$ & $\mathbf{1 0 0 \%}$ \\
\hline
\end{tabular}

The result from the table above shows that miscellaneous is the dominant type while the least amount data is sound of nature. A total of miscellaneous is 67 onomatopoeia or $55.4 \%$ while a total sound of nature is 10 onomatopoeia or $8.3 \%$. From the total data, the onomatopoeia that are produced dominantly come from the sound of an object or an inanimate thing. 


\subsection{Call of Animals}

Call of animals or sound of animals is a type that refers to the words that imitate the sound produced by an animal. The sound can be either the movement activities or sound of animals itself. Thomas and Clara mentioned that call of animals is an imitation of sounds originating from animals.

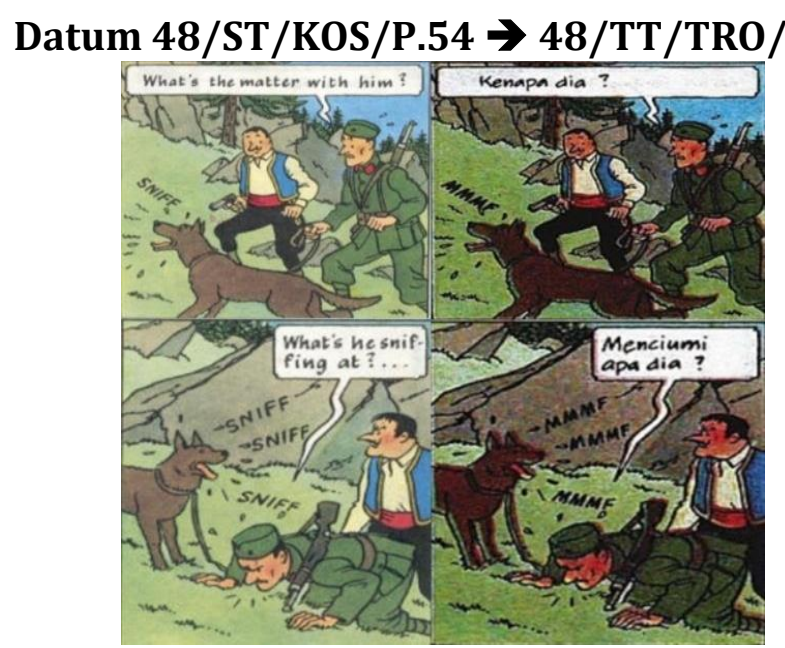

Figure 1.1. The onomatopoeia of sound of a dog sniffing

In this example, there are onomatopoeia SNIFF (SL) and $\boldsymbol{M} M \boldsymbol{M} \boldsymbol{F}$ (TL). The data is taken from the series of comic entitled King Ottokar's Sceptre (SL) or Tongkat Raja Ottokar (TL). The onomatopoeia SNIFF and MMMF are the words which imitate the sound of a dog sniffing the ground. We can see at the figure above, there was a dog who was chasing something. It suddenly stopped its steps and started to sniff. It was proven when a man in the figure asked what thing the dog sniffed at. The other clue is because the onomatopoeia SNIFF is from the word sniffing. Sniff means to breathe air in through the nose in a way that makes a sound. So, the onomatopoeia $\mathbf{S N I F F}$ and $\boldsymbol{M M M F}$ are classified into call of animals.

\subsection{Sound Made by Humans}

Sound made by human is the type of onomatopoeia that refers to a word that is produced by imitating the sounds made by a human being. It can be the human activity such as sound of drinking/gulping, sound of blowing a hot food and the sounds that are produced by the part of body of human such as sound of snoring, crying, farting and sound of falling to the ground. 


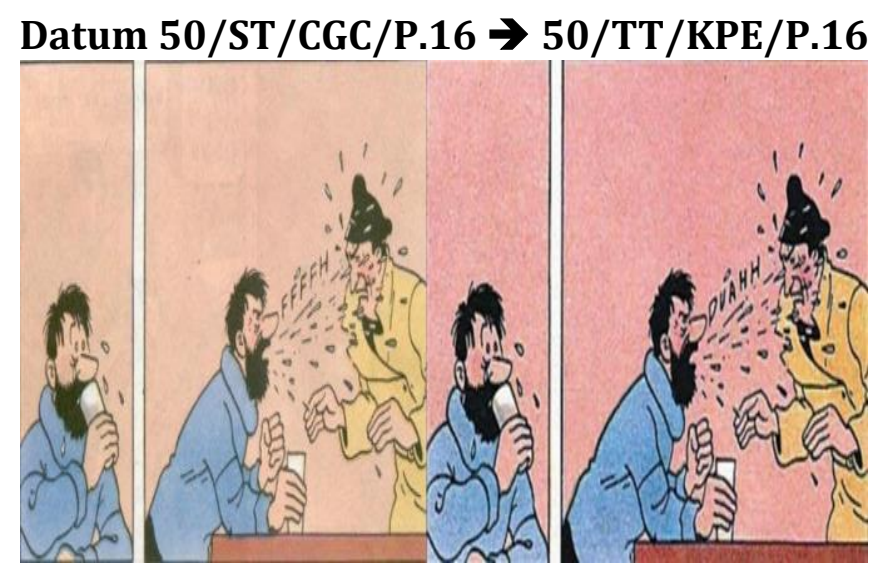

Figure 1.2.

The onomatopoeia of the sound of a man spouting the water from the mouth

In the example of figure 1.2 shows the onomatopoeia of a man spouting water from his mouth. The data is taken from the comic series entitled The Crab with the Golden Claws (SL) or Kepiting Bercapit Emas (TL). From the figure in the panel, there was a man drinking a glass of water, but suddenly spouted the water from his mouth and splashed another man close to him. The onomatopoeia which appear when the man spouted the water are $\boldsymbol{F F F F H ~ ( S L ) ~ a n d ~ D U A H H ~ ( T L ) . ~ F r o m ~}$ the explanation, the onomatopoeia $\boldsymbol{F F F F H}$ and $\boldsymbol{D} \boldsymbol{U} \boldsymbol{A H H}$ are categorized as the type of onomatopoeia of sound made by humans.

\subsection{Sound of Nature}

The onomatopoeia of sound of nature refers to a word which imitates the sound that is produced by nature or physical phenomena. They can be a sound of water dripping, sound of the broken branch, sound of a wave, etc. Also, sound of nature are from natural phenomena such as sound of a wind, sound of a storm, sound of thunder and rain.

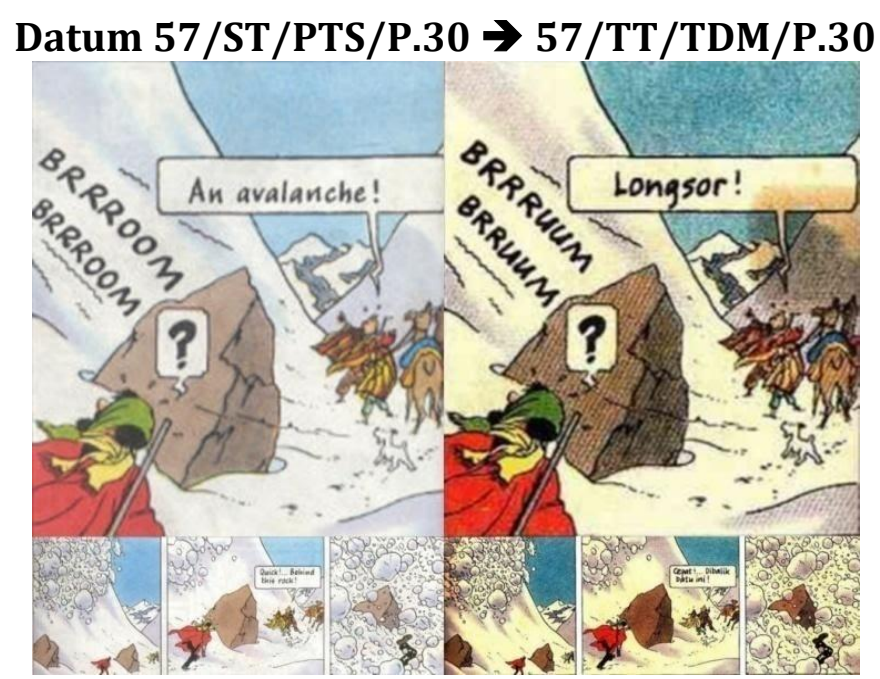

Figure 1.3. The onomatopoeia of sound of an avalanche 
In figure 1.3 is the one of examples of sound of nature. There are onomatopoeia BRRROOM BRRROOM (SL) and BRRRUUM BRRRUUM (TL) which represent the sound of an avalanche. The data is taken from the comic series entitled Prisoners of the Sun (SL) or Tawanan Dewa Matahari (TL), in the figure of panel shows that there are some people who were walking in a snow mountain when one of them shouted that an avalanche would come. After that, the next figure showed the snow falling down and hoarded one of them. Consequently, the onomatopoeia BRRROOM BRRROOM (SL) and BRRRUUM BRRRUUM (TL) are categorized as the word imitation of sound of nature.

\subsection{Miscellaneous Sound}

Miscellaneous is a type of onomatopoeia which imitates the sound that is produced by an inanimate object such as the sound of a door being opened, a bell ringing, sound of a bomb, etc.

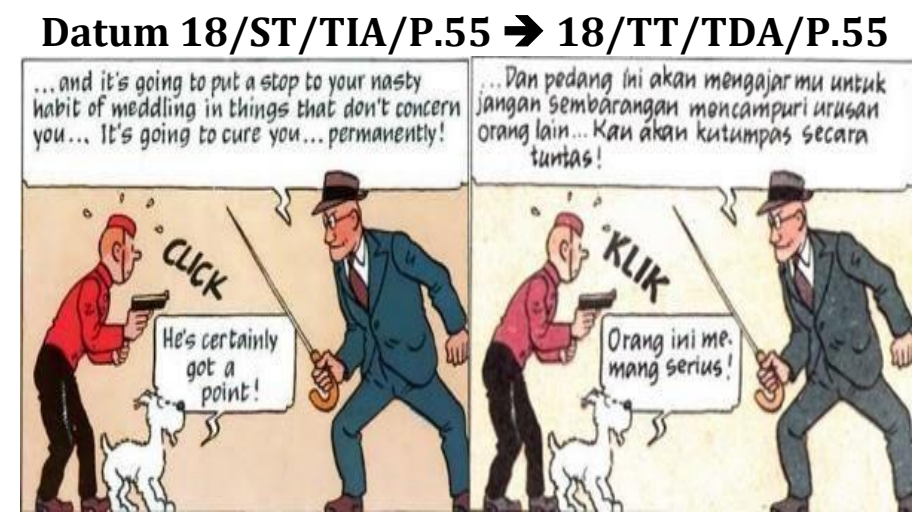

Figure 1.4. The onomatopoeia of sound of an empty gun

There are onomatopoeia CLICK (SL) and $\boldsymbol{K L I K}$ (TL) as the example of miscellaneous and they represent the sound of an empty gun. In the data which is taken from the comic series Tintin in America (SL) or Tintin di Amerika shows that there was a young man with a gun in his hand and his dog facing a man who was bringing a sword. At the same time a young man seemed starting to shoot the gun. Unfortunately the gun was empty and the young man seemed confused and scared. Therefore, we can conclude that the onomatopoeia CLICK (SL) and KLIK (TL) are categorized as miscellaneous sound.

Furthermore, types of onomatopoeia are classified from the source of sounds that are produced. The figure or visual elements also the dialogues between the characters help so much in classifying the onomatopoeia. Some onomatopoeia are not followed by dialogues but the picture can explain the situation of context. The English and Indonesian versions have the same types of each onomatopoeia but they have different expressions in resembling the sound of the objects. The reason is because the sources of sound come from the same objects. For example, in figure 1.4 which shows the onomatopoeia of sound of clicking an empty gun, the English version will be CLICK and in Indonesian it is translated into KLIK. Although they have different onomatopoeia but they have the same types because the source of sound comes from the same object. 


\section{Techniques of Translation}

As Molina and Albir (2002: 509) proposed, technique of translation can be stated as the procedures or steps that are used to transfer the ST into TT which consider the micro units of text such as word, phrase, clause and sentence. From all eighteen translation techniques that are proposed by Molina and Albir, the researcher only found five techniques that are implemented in 21 series of The Adventure of Tintin comic to transfer the onomatopoeia.

Table 2. Translation Techniques of All the Translated Onomatopoeia

\begin{tabular}{|c|c|c|c|}
\hline No. & Translation Techniques & Total & Percentages \\
\hline 1. & Adaptation & 6 & $5 \%$ \\
\hline 2. & Borrowing & 42 & $34.7 \%$ \\
\hline 3. & Discursive Creation & 23 & $19 \%$ \\
\hline 4. & Established Equivalent & 45 & $37.2 \%$ \\
\hline 5. & Reduction & 5 & $4.1 \%$ \\
\hline \multicolumn{2}{r}{ Total Data } & $\mathbf{1 2 1}$ & $\mathbf{1 0 0 \%}$ \\
\hline
\end{tabular}

As the table displayed, there are two of the most dominant techniques implemented in The Adventure of Tintin comic which are borrowing and established equivalents. A total of 42 or $34.7 \%$ of translated onomatopoeia belong to borrowing technique and 45 of translated onomatopoeia or $37.2 \%$ belong to established equivalent technique. Translator tends to use common terms in target language to translate the onomatopoeia to make the situation of context are easier to understand. Moreover, the translator often copies or changes a little bit of letter from source text in some onomatopoeia which do not have the equivalent meaning in target language. Moreover, the discursive creation technique has 23 translated onomatopoeia or $19 \%$ data. This technique is used when there is no word that has the same form and meaning in target language. Translator that uses this technique tends to change the text with unpredictable words or the words that can explain or express the situation temporarily. Furthermore, the least techniques that are implemented in The Adventure of Tintin comic are adaptation and reduction. A total of 6 or $5 \%$ translated onomatopoeia belong to adaptation technique as well as 5 or $4.1 \%$ translated onomatopoeia belong to reduction technique. It shows that the translator rarely transfers the ST by adjusting the cultural element in TT.

\subsection{Adaptation}

Adaptation technique as explained by Molina and Albir (2002: 506) replaces the term in source language by adjusting the element of culture in target language. Therefore, this technique will make the readers who are unfamiliar with the term provided in source text to know and understand the situation of context from the onomatopoeia better. 


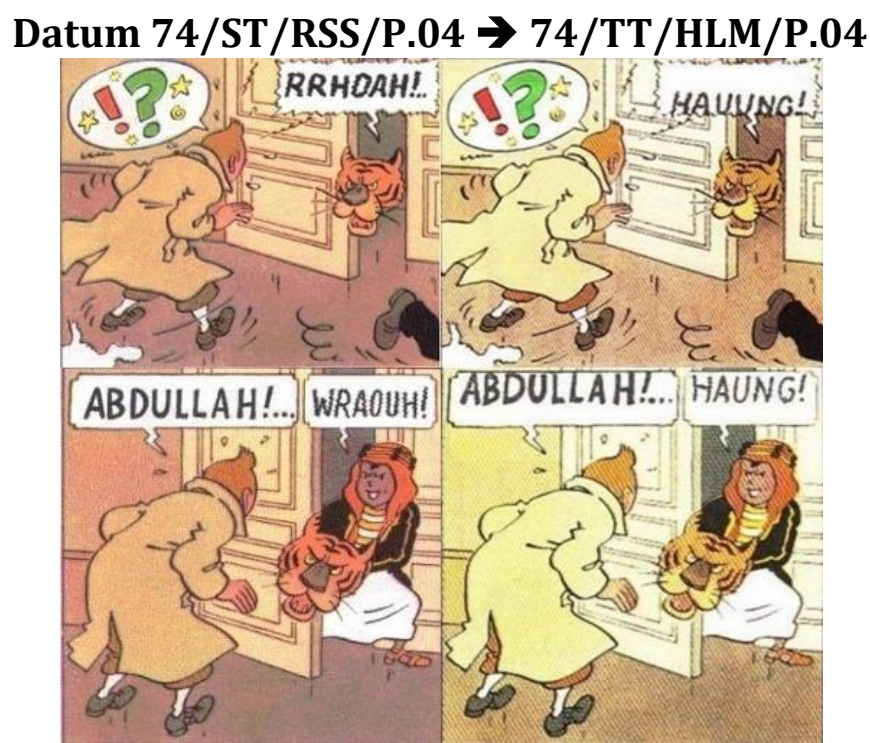

Figure 2.1. The onomatopoeia of a kid frighten the other man with sound of tiger

The example is taken from the comic series entitled The Red Sea Sharks (SL) or Hiu-hiu Laut Merah (TL). The onomatopoeia describes the sound of a kid frighting a man with the sound of a tiger RRHOAH! (SL) and HAUUNG! (TL). Figure 2.1 shows there was a kid behind the door holding out a tiger mask or tiger doll. Some readers are familiar with the imitation of tiger sound. In Indonesian, the sound of tiger that is commonly used is HAUUNG! or RAUUNG!. Therefore, it is included to the adaptation technique.

\subsection{Borrowing}

Borrowing is a technique of translation which replaces or transfers word or phrase to another language by bringing the terms from the source text or translator only changes a little bit of letter from the word itself. It can be copied, reduced, or changed the source text (ST) into target text (TT). There are two kinds of borrowing technique, i.e. pure borrowing which does not change any word and naturalized borrowing which has been naturalized in order to fit the spelling rules in target language (TL). This technique is used when there is no good equivalence meaning or form in target language.

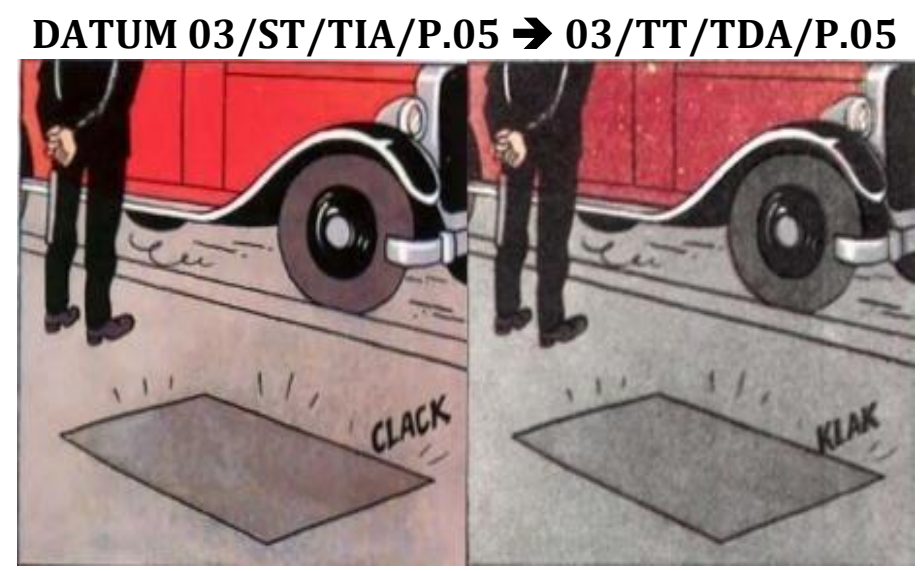

Figure 2.1. The onomatopoeia of sound of a trap being closed 
In this example that is taken from the comic series entitled Tintin in America (ST) or Tintin di Amerika (TT) that is classified used borrowing technique. The onomatopoeia imitates the sound of a trap being closed which sound CLACK (ST) and it is changed into $\boldsymbol{K} \boldsymbol{L A K}$ (TT). The translator borrows the word from source text (ST) and changes only one letter from the source text and reduces a letter to fit the spelling rules in Indonesian, so that the technique is included into naturalized borrowing. The translated onomatopoeia still has same characteristic with the source text. Therefore, the translated onomatopoeia is identified used borrowing technique.

\subsection{Discursive Creation}

Discursive creation is the translation technique that changes the word or term in source text (ST) by using the unpredictable text or word. The translator tends to define and create the temporary equivalent that is out of context. The translator uses this technique when there is no equivalent meaning in target language, so they will create a temporary equivalent.

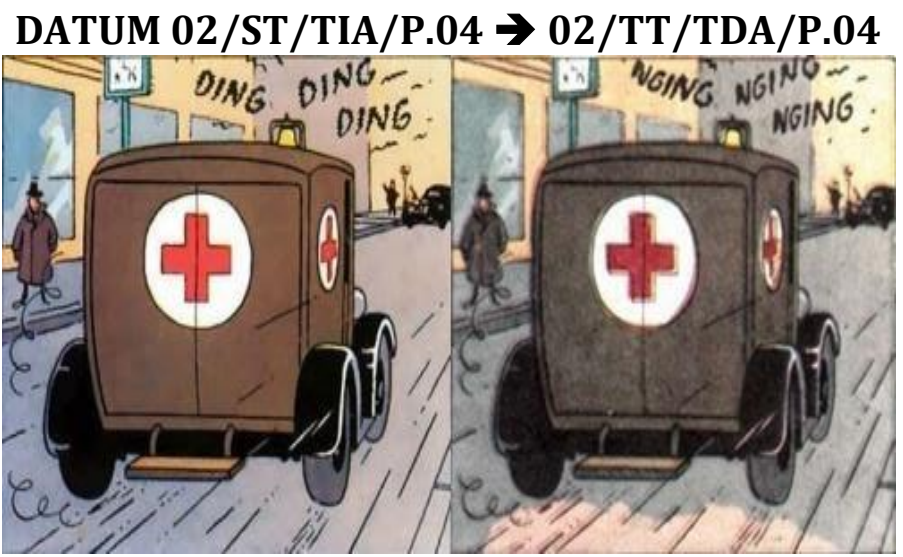

Figure 2.3. The onomatopoeia of sound of ambulance siren

This onomatopoeia is taken from the comic series entitled Tintin in America (ST) or Tintin di Amerika (TT) is identified used discursive creation technique. The onomatopoeia of ambulance siren sounds DING DING DING in source text then the translator translates it into NGING NGING NGING in target text. The use of onomatopoeia of DING DING DING in English is commonly used to represent the sound made by a bell but in this data this is used to represent the sound of ambulance siren. While the use of words NGING NGING NGING sounds unfamiliar and unpredictable. In this data, the source text as well as the target text do not convey its purpose in expressing the sound of an ambulance siren. The reason is because the onomatopoeia does not sound natural. In Indonesian, it will be more familiar with sounds NGUING NGUING NGUING or WIUWIUWIUW than NGING NGING NGING to describe the sound of ambulance siren. As defined in $K B B I$ (Kamus Besar Bahasa Indonesia), the word NGING is brought from the word DENGING which is the word that is used to describe the sound of a bee or mosquito. Therefore, the word NGING NGING NGING in this case is included to unpredictable word to translate the onomatopoeia of sound of ambulance sirens. 


\subsection{Established Equivalent}

Established Equivalent is the technique which translates a word or term from source language into another language by using the common and familiar terms in target language or in dictionary. The translators use this technique in transferring a word if there is an equivalent meaning in target language. In the case of translating onomatopoeia, the translators use the familiar onomatopoeia in society or create the onomatopoeia itself by hearing sound that represents something.

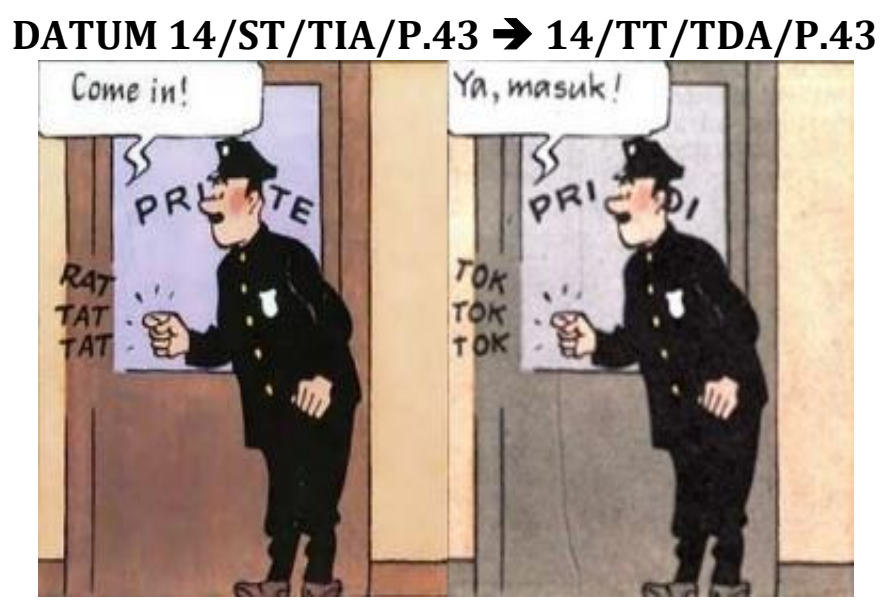

Figure 2.4. The onomatopoeia of sound knocking the door

This instance is taken from comic series entitled Tintin in America (ST) or Tintin di Amerika (TT) that is also identified used established equivalent technique. The figure above shows a man knocking the door and the sound is RAT TAT TAT in source language and TOK TOK TOK in the target language. In English, the onomatopoeia KNOCK KNOCK is more familiar to represent the sound of knocking the door than using the words RAT TAT TAT. In this data, the English version uses the unfamiliar onomatopoeia. On the other hand, the use of onomatopoeia TOK TOK TOK in Indonesian sounds natural and familiar in target language. Therefore, the established equivalent technique is identified used in this data.

\subsection{Reduction}

This technique includes to the process of suppressing or compressing when transferring the information of source language (SL) into target language (TL). In suppressing the information, this technique reduces certain element of source language. It is also called elimination, omission or subtraction. 


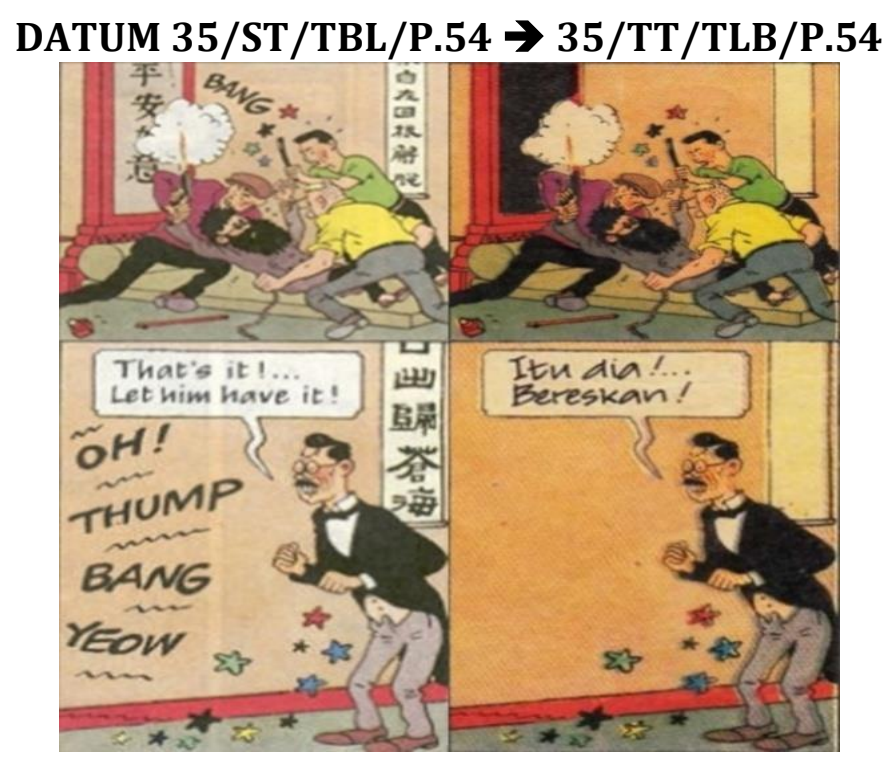

Figure 2.5. The onomatopoeia of the sound of people making some noise

In this example which is taken from the comic series entitled The Blue Lotus (ST) or Tintin dan Lotus Biru (TT), there is an onomatopoeia of people making some noise which is represented as OH! THUMP BANG YEOW and it is omitted by the translator in target text so there is no onomatopoeia that is provided in target text. From the context of situation, people in general are more familiar with the onomatopoeia AUW! BAK BUK DOR ADUH as representation of sound of people making some noises in Indonesian. Nonetheless, the translator does not translate the onomatopoeia into Indonesian version. Therefore, the technique that is used by the translator is reduction.

\section{Translation Acceptability}

Acceptability of translation is included in the quality of translation that is proposed by Nababan (2012: 44) besides accuracy and readability. Translation acceptability measures the quality of translated text particularly in aspect of rules, norms and culture of target language whether or not the translated text can be naturally accepted by the readers. In this part, the assessment is divided into three levels, there are acceptable, less acceptable and unacceptable. Each level of assessment of translation acceptability will be discussed further why the translated onomatopoeia and their technique are acceptable or why they identify as less acceptable and unacceptable.

Table 3. The Result of Acceptability Assessment

\begin{tabular}{|c|c|c|c|}
\hline No. & Acceptability Level & Total & Percentages \\
\hline 1. & Acceptable & 99 & $82 \%$ \\
\hline 2. & Less Acceptable & 18 & $15 \%$ \\
\hline 3. & Unacceptable & 4 & $3 \%$ \\
\hline \multicolumn{2}{|c|}{ Total Data } & $\mathbf{1 2 1}$ & $\mathbf{1 0 0 \%}$ \\
\hline
\end{tabular}


As we can see in the table of result above, the dominant one is acceptable which has 99 translated onomatopoeia or 82\%. While less acceptable and unacceptable levels are found in the data source although they have a little bit of data. The amount of data for less acceptable is 18 translated onomatopoeia or $15 \%$ while unacceptable is 4 or $3 \%$. The further explanation will be elaborated below.

\subsection{Acceptable}

Acceptability can be defined as a custom, in case of translation, a term or word which is considered common, natural or proper in certain community. The natural or common words can be different in each community. The high level acceptability of translation can produce the natural translation products and it is easier to be understood by the readers. Consequently, the translated text is considered suitable with the cultural and grammatical rules of target language.

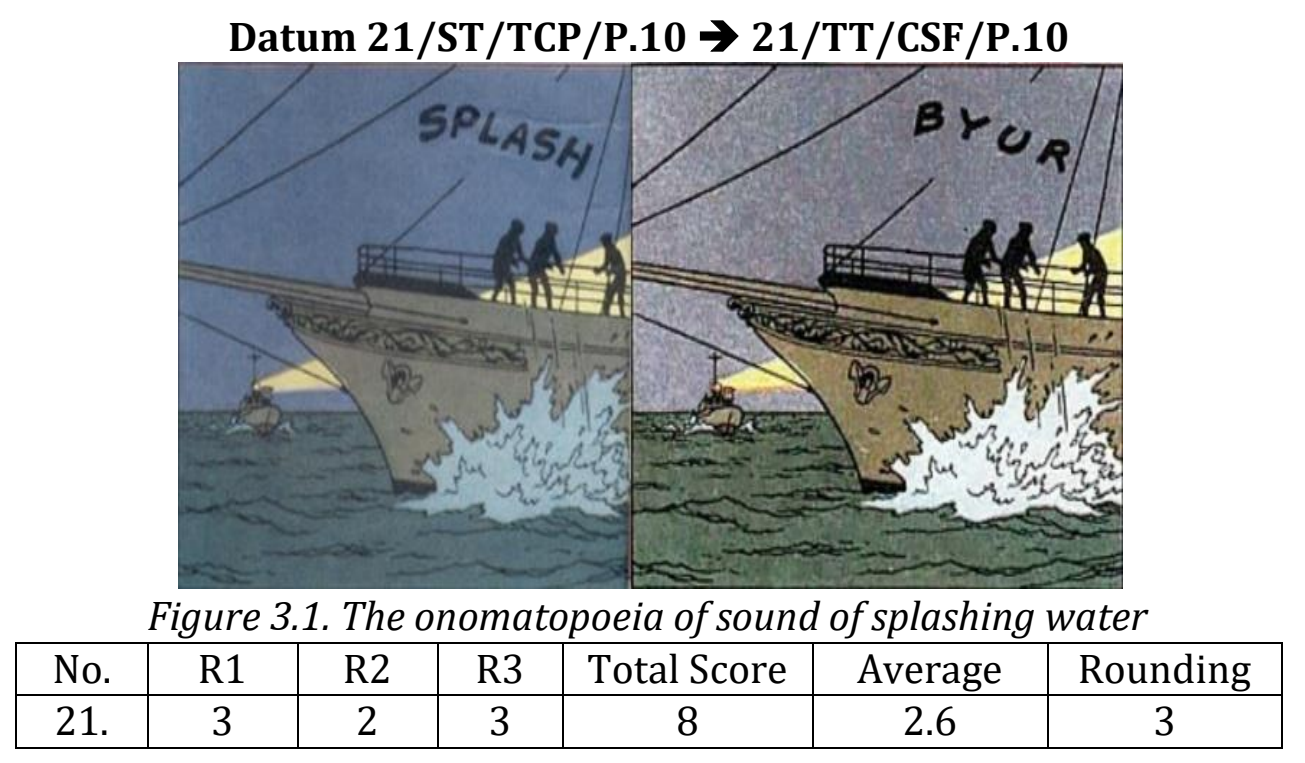

The example is the datum number 21 which also uses established equivalent technique and it is successfully translated to natural and familiar onomatopoeia. Therefore, some respondents give high score for the onomatopoeia SPLASH (ST) that is translated into BYUR (TT). Since the onomatopoeia BYUR is stated in KBBI (Kamus Besar Bahasa Indonesia) as the word that describes sound of splashing water which is common and sounds natural in Indonesian. Two respondents also agree with the onomatopoeia and give high score of this datum. One of them suggests to use the term SPLASH in target language. The researcher convinces that BYUR is better than bringing the word SPLASH from source language. The reason is because the word $\boldsymbol{B Y U R}$ is more natural in society. For this reason, the implementation of established equivalent technique is quite successful to translate the onomatopoeia of sound of splashing water. 


\subsection{Less Acceptable}

As Nababan (2012: 44) defined, less acceptable in general means the translation products are already natural, however, there are few problems in the use of technical terms that can lead to either grammatical and cultural errors. This level is medium of acceptability assessment and it is considered less acceptable. Also, the message of translation product is still conveyed and it can be understood by the readers.

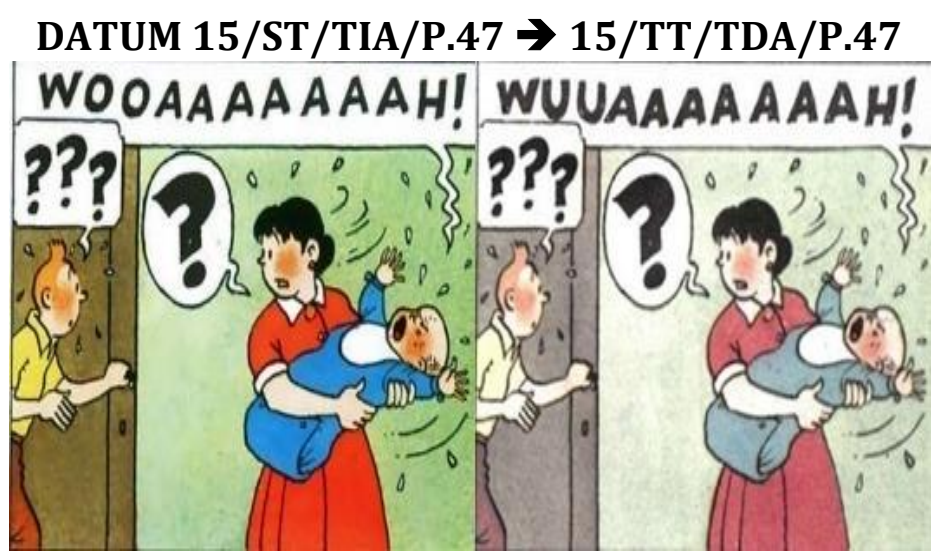

Figure 3.2. The onomatopoeia of sound of baby was crying

\begin{tabular}{|c|c|c|c|c|c|c|}
\hline No. & R1 & R2 & R3 & Total Score & Average & Rounding \\
\hline 15. & 3 & 2 & 1 & 6 & 2 & 2 \\
\hline
\end{tabular}

This datum is acquired from the comic series entitled Tintin in America (ST) or Tintin di Amerika (TT). The onomatopoeia represents the sound of baby who was crying and produced the onomatopoeia WOOAAAAAAAH! in source text then it is changed into WUUAAAAAAAH!. The result of questionnaire shows that the translated onomatopoeia is categorized less acceptable. After rounding the score, the datum gets two of average scores. The technique that is used to translate this datum is borrowing. The reason why this datum is categorized less acceptable is because the term is uncommon to target language. The first respondent suggests the onomatopoeia $\boldsymbol{E A A A K} \boldsymbol{E A A K} \boldsymbol{E A A K}$ and the second one suggests the onomatopoeia $\boldsymbol{O E E} \boldsymbol{O E E}$ to represent the sound of baby crying. The researcher

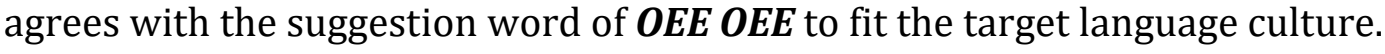

\subsection{Unacceptable}

In this part, the translated onomatopoeia that cannot be understood easily are categorized as an unacceptable translation. It can be seen through how the onomatopoeia works to represent or describe the sound of an object. This assessment is identified as the lowest level of acceptability. The use of term or onomatopoeia tends to be uncommon and unfamiliar in target language and it does not sound natural. 


\section{DATUM 105/ST/TFS/P.35 $\rightarrow$ 105/TT/PT/P.35}

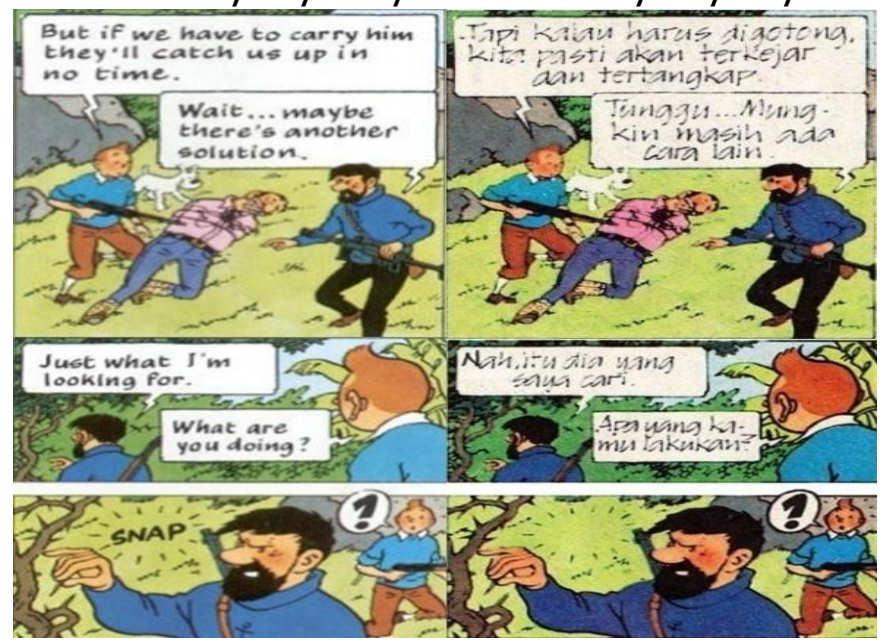

Figure 3.3. The onomatopoeia of sound of a thorn was plucked from a tree

\begin{tabular}{|c|c|c|c|c|c|c|}
\hline No. & R1 & R2 & R3 & Total Score & Average & Rounding \\
\hline 105. & 1 & 1 & 1 & 3 & 1 & 1 \\
\hline
\end{tabular}

This datum is acquired from the comic series entitled The Flight 714 (ST) or Penerbangan 714 (TT). In datum number 105, there is an onomatopoeia SNAP which represents the sound of a thorn being plucked from the tree by a man. The onomatopoeia is not translated in the target text by the translator so that this datum is categorized as reduction technique since the translator omits the word in target language. For the result, the readers in target language cannot know and understand the context of situation as there is no expression or onomatopoeia to describe the sound of the activity. The figure also feels less alive. For those reason, this datum got 1 score from each respondent and leads this translated onomatopoeia to be unacceptable. Furthermore, the first and second respondents suggest the word TAK or PLUK to represent the sound of a thorn being plucked from a tree. The researcher also agrees with the two suggestions, they will be more familiar to the target language.

\section{CONCLUSION}

After analyzing the data based on types of onomatopoeia, translation techniques and translation acceptability, the researcher concludes the following patterns:

1. There are 121 onomatopoeia found in 21 comic series of The Adventure of Tintin comic. The types of onomatopoeia that are found in all series of comic are call of animals (23 data), sound made by humans (21 data), sound of nature (10 data) and miscellaneous sound (67 data).

2. From all eighteen techniques that are proposed by Molina and Albir (2002: 509), the techniques that are implemented in comic are only five techniques. They are adaption ( 6 data), borrowing (42 data), discursive creation (23 data), established equivalent (45 data) and reduction (5 data).

3. In this research, all of acceptability levels are identified. For the details of three levels of translation acceptability are: 99 translated onomatopoeia or $82 \%$ are identified as acceptable which is highest level of acceptability, the 
number of less acceptable or medium level reaches 18 translated onomatopoeia or $15 \%$ and 4 translated onomatopoeia or $3 \%$ belong to unacceptable and categorized as lowest level of acceptability.

In conclusion, the techniques of translation that are used by the translator in translating the onomatopoeia in this comic can affect the quality of translation. Further, the most implemented techniques in this comic is classified as established equivalent, which are the uses of this technique mostly get the high score of acceptability level and lead to be considered as acceptable translation. Meanwhile the uses of reduction technique are mostly considered as less acceptable and even unacceptable. Thus, the translated onomatopoeia in The Adventure of Tintin comic are generally understandable, sound familiar and natural to target language so that it can strengthen the sense of reality of situation context.

\section{REFERENCES}

Cohn, Neil. (2005). Un-Defining 'Comics' in International Journal of Comic Art, Vol. 7. No. 2, 2005.

Creswell, J. W. (2007). Research Design: Qualitative, Quantitative, Mixed Methods Approaches. Thousand Oaks. California: Sage.

Kamus Besar Bahasa Indonesia (edisi ke V). 2016. Badan Pengembangan dan Pembinaan Bahasa.

Lestari, Flori. (2014). Onomatopoeia Translation in Wreck-It Ralph The Movie. Jakarta: State Islamic University Syarif Hidayatullah.

Molina, L \& Albir. A.H. (2002). Translation Technique and Revisited: A Dynamic and Functionalist Approach in Meta: Translation's Journal, XLVII, 4. Pp. 498512.

Nababan, M, Nuraeni, A \& Sumardiono. (2012). Pengembangan Model Penilaian Kualitas Terjemahan dalam Jurnal Kajian Linguistik dan Sastra, Vol. 24. No. 1, 2012. Pp. 39-57.

Nazir, Moh. (2005). Metode Penelitian. Bogor: Ghalia Indonesia.

O’Grady, William. (2005). Contemporary to Linguistics: An Introduction. New York: Bedford Book.

Pertiwi, Dewi Hana. (2015). Translation of Onomatopoeia and Iconicity in Children Story Book: Crocoffein-Coffee of Friendship by Watiek Ideo and Fitri Kurniawan. Jakarta: State Islamic University Syarif Hidayatullah.

Thomas, Tsoi Wai Chuen, and Clara, Chung Hoi Wai. (2004). Characteristics of Onomatopoeia." LIN1001 Discovering Linguistics. 